\title{
Study of Watershed Image Segmentation for Flood Potential Area Mapping in Jakarta Case Study: Ciliwung River-West Banjir Kanal
}

\author{
Indra Riyanto ${ }^{\mathrm{a}}$, Lestari Margatama ${ }^{\mathrm{b}}$ \\ ${ }^{a}$ Department of Electrical Engineering, Faculty of Engineering, Budi Luhur University \\ ${ }^{\mathrm{b}}$ Department of Informatics Engineering, Fac. of Information Technology, Budi Luhur University \\ E-mail: indra.riyanto@budiluhur.ac.id
}

\begin{abstract}
The recent degradation of environment quality becomes the prime cause of the recent occurrence of natural disasters. It also contributes in the increase of the area that is prone to natural disasters. Flood history data in Jakarta shows that flood occurred mainly during rainy season around January - February each year, but the flood area varies each year. This research is intended to map the flood potential area in DKI Jakarta by segmenting the Digital Elevation Model data. The data used in this research is contour data obtained from DPPDKI with the resolution of $1 \mathrm{~m}$. The data processing involved in this research is extracting the surface elevation data from the DEM, overlaying the river map of Jakarta with the elevation data. Subsequently, the data is then segmented using watershed segmentation method. The concept of watersheds is based on visualizing an image in three dimensions: two spatial coordinates versus gray levels, in which there are two specific points; that are points belonging to a regional minimum and points at which a drop of water, if placed at the location of any of those points, would fall with certainty to a single minimum. For a particular regional minimum, the set of points satisfying the latter condition is called the catchments basin or watershed of that minimum, while the points satisfying condition form more than one minima are termed divide lines or watershed lines. The objective of this segmentation is to find the watershed lines of the DEM image. The expected result of the research is the flood potential area information, especially along the Ciliwung river in DKI Jakarta.
\end{abstract}

Key words : Remote Sensing, Image Processing, Watershed Image Segmentation, Daerah Aliran Sungai, Digital Elevation Model

\section{INTRODUCTION}

Flood is always having a significant impact on the affected area, either directly or indirectly, especially on the people that lived around the river or in the floodplain. Some major flood occurrences in tropical area are caused by monsoons which pushed the sea into the land, which in turn slows the river flow on the river mouth. The slowdown of the flow causes the riverbank to overflow and became flash flood on areas with low elevation.

The city of Jakarta is situated on a floodplain, where $40 \%$ of its area lies below sea level. Rapid growth of the city without adequate water supply system causes high usage of sub-surface water which in turn causes land subsidence. This condition is also complicated by the degradation of the city's drainage and sewer system, including downtown rivers. Floods are phenomena that occurs almost every year in Jakarta, with some occurrences are unusually severe, notably the major floods in 1996, 2002, and 2007. Flood in Jakarta usually occurs in the peak of the rainy season on JanuaryFebruary of each year [1]. This research is to map potential flood areas based on 2007 flood data by the use of Digital Elevation Model (DEM) data and Landsat 7 image as supporting data. The result from this research is the flood prediction model from DEM to support and enrich the information on flood monitoring and control by the local or provincial administrative bodies.

\section{Remote Sensing And Image Processing}

\section{A. Remote Sensing System}

Remote Sensing is defined as a science to obtain information about objects on the surface of the earth with the data analysis obtained from remote sensing devices. Generally, remote sensing is used to identify the surface of the earth by the means of electromagnetic radiation that reflected or emitted by the earth's surface. Every object on earth surface not only reflects or scatters part of incident electromagnetic energy but also emits radiation according to its temperature and emissivity [2]. Specifically, satellites are used as sensorcarrying platform with imaging sensors to perform the task as remote sensing satellites.

The detection and discrimination of objects or earth surface comprises of detecting and recording of radiated energy reflected or emitted by the objects or surface materials. Different objects will give different value and type in electromagnetic spectrum. Remote sensing system using sensors carried by satellites or aircraft can be passive or active in nature. Active sensor system uses energy emitted by the platform itself, while a passive sensor depends on the object's emission or illumination from the sun. Optical image data is obtained by passive sensor system, while surface contour data and radar images are obtained from active sensors. Figure 1 shows remote sensing system with its components [3]. $A$ is the illumination source, either from the sun or from the platform itself. The electromagnetic wave travels 
through the atmosphere (B) and is reflected by the object(s) on the surface. The reflected energy is detected by sensor on the platform $D$ and (E) transmitted by side-link to relay satellite or down-linked to ground control station. The collected data is processed $(\mathrm{F})$ to provide spatial correction, etc. before being further processed and analyzed as final data $\mathrm{G}$.

DEM is a digital representation of the surface topography. DEM found many use in geographic information system and became the basis of most digital relief mapping process. In digital mapping, each part of the map is divided into blocks. The gradient in each block is irregular that it needed to minimize the gradient variability in one block. Theoretically, this variability can be reduced by reducing the gradient angle interval used as block-dividing criteria. Practically, smaller interval increases the difficulty in the mapping process [4].

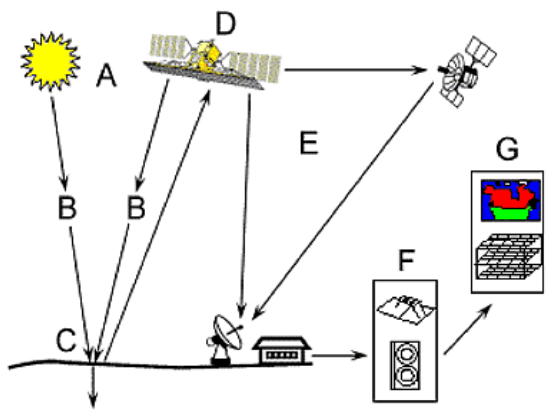

Figure 1. Remote Sensing System [3]

The non-military use of earth observation satellite is pioneered by the TIROS satellite for weather and cloud pattern observation and wide-scale use is initiated with Landsat (Land Satellite) program to map the earth. Landsat series begin with Landsat-1 operating between 1972 and 1978 and followed by subsequent satellite in the series, except Landsat-6 which destroyed during launch. The current Landsat-7 begin operating from 1999, with the most recent data suffering from degradation due to component malfunction. This problem prompts the Landsat Data Continuity Mission (LDCM) to sustain the availability of earth surface observation.

\section{B. Image Segmentation}

Digital image processing methods stems from two principal application areas: improvement of pictorial information for human interpretation; and processing of image data for storage, transmission, and representation for autonomous machine perception. An image may be defined as a two-dimensional function, $f(x, y)$, where $x$ and $y$ are spatial (plane) coordinates, and the amplitude of $f$ at any pair of coordinates $(x, y)$ is called the intensity or gray level of the image at that point. When $x, y$, and the amplitude values of $f$ are all finite, discrete quantities, the image is called a digital image [5]. In the field of remote sensing, image analysis is done on digitally represented images with overhead perspective; since it is represented in numerical value, the image can be easily manipulated.

Image segmentation process subdivides an image into its constituent regions or objects. Segmentation process should stop when the objects of interest in an application have been identified, there is no point in carrying segmentation past the level of detail required to identify those elements. Segmentation of nontrivial images is one of the most difficult tasks in image processing. Segmentation accuracy determines the eventual success or failure of computerized analysis procedures. Image segmentation algorithms are generally based on one of two basic properties of intensity values: discontinuity and similarity. In the first category, the approach is to partition an image based on abrupt changes in intensity, such as edges in an image. In digital image there are three kinds of discontinuities: point discontinuity, line discontinuity, and edge discontinuity. The principal approaches in the second category are based on partitioning an image into regions that are similar according to a set of pre-defined criteria.

In this section we discuss an approach based on the concept of the so-called morphological watersheds. Segmentation by watersheds embodies many of the concepts of detection of discontinuities, thresholding, and region processing, and, as such, often produces more stable segmentation results, including continuous segmentation boundaries. This approach also provides a simple framework for incorporating knowledge-based constraints in the segmentation process.

The concept of watersheds is based on visualizing an image in three dimensions: two spatial coordinates versus gray levels. In such a "topographic" interpretation, we consider three types of points: (a) points belonging to a regional minimum; (b) points at which a drop of water, if placed at the location of any of those points, would fall with certainty to a single minimum; and (c) points at which water would be equally likely to fall to more than one such minimum. For a particular regional minimum, the set of points satisfying condition (b) is called the catchment basin or watershed of that minimum. The points satisfying condition (c) form crest lines on the topographic surface and are termed divide lines or watershed lines. The principal objective of segmentation algorithms based on these concepts is to find the watershed lines.

One of the principal applications of watershed segmentation is in the extraction of nearly uniform (bloblike) objects from the background. Regions characterized by small variations in gray levels have small gradient values. Thus, in practice, we often see watershed segmentation applied to the gradient of an image, rather than to the image itself. In this formulation, the regional minima of catchment basins correlate nicely with the small value of the gradient corresponding to the objects of interest.

With $\mathrm{M}_{1}, \mathrm{M}_{2}, \ldots, \mathrm{M}_{\mathrm{R}}$ are sets denoting the coordinates of the points in the regional minima of an image $g(x, y)$. T $[n]$ represent the set of coordinates $(s, t)$ for which $g(s, t)<\mathrm{n}$. That is, 


$$
\mathrm{T}[n]=\{(s, t) \mid g(s, t)<\mathrm{n}\}
$$

Geometrically, $\mathrm{T}[n]$ is the set of coordinates of points in $g(x, y)$ lying below the plane $g(x, y)=n$. The topography will be flooded in integer flood increments, from $n=\min +1$ to $n=\max +1$. At any step $n$ of the flooding process, the algorithm needs to know the number of points below the flood depth. The coordinates in $\mathrm{T}[n]$ that are below the plane $g(x, y)=n$ are "marked" black, and all other coordinates are marked white. Figure 2 shows the watershed process. If $C_{n}\left(M_{i}\right)$ denote the set of coordinates of points in the catchment basin associated with minimum $M$, that are flooded at stage $n . C_{n}\left(M_{i}\right)$ may be viewed as a binary image given by

$$
C_{n}\left(M_{i}\right)=C\left(M_{i}\right) \cap T[n]
$$

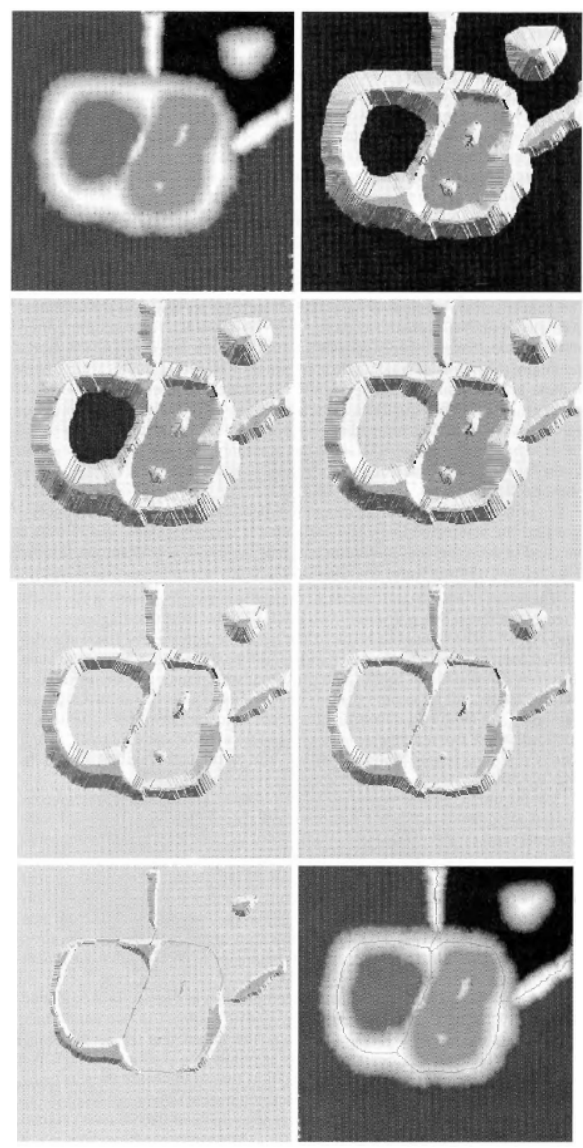

Figure 2. The watershed segmentation process [5]

In Figure 2, top left image shows the basic image to be segmented, to right shows the distance transformation for each pixel of the object, which now shows a ridgelike pattern. The next two rows shows the steps of "submerging", which is converting the value of the objects' outermost pixel to that of the background's. the bottom left shows the watershed lines of the object. This line then superimposed to the original image as shown in the bottom right image.

\section{JAKARTA WATERSHED CHARACTERISTICS}

Land gradient in Jakarta area is relatively homogeneous, but in some places there are gradients of $4^{\circ}$ to $20^{\circ}$ which is typically in the southern part and on the riverbanks [6]. The flatness of the area is also evident in the rivers that flows through downtown Jakarta, which has many meanders. With generally low elevation and some areas being lower than sea level, and passed by 14 rivers with dendritic pattern, Jakarta is naturally very prone to flooding. This problem has been addressed by the Dutch colonial government by digging flood canal to the south and west of the then-Batavia city by diverting some flow of the Ciliwung river before entering Batavia to the west of the city before discharged to the sea. This canal, commonly caled Banjir Kanal Barat (west Banjir Kanal) is now absorbed by the growth of Jakarta and located in Central Jakarta Municipality. Recently, the government of Jakarta Special Capital Region is making the second flood canal to the east of the city. These canals are expected to absorb most of the river overflows that can cause floods in downtown areas.

Other than the canals, Jakarta public works service also maintains drainage system to minimize flood occurrence, it comprises of rivers and streams as main drainage system, complemented by a system of gates and pump installations to regulate the riverflow. The pumps are also used to move excessive deposit of riverflow to main drainage system and/or to artificial reservoirs which acts as water catchment area.

\section{Flood Area Segmentation}

For the west Banjir Kanal area, the land elevation data is being made into grid pattern of the surface to obtain the surface contour with elevation resolution of 2 meters. The contour shown in Figure 3 is relatively homogenous since the canal is located in central flatland, is comprised of three dominant elevation ranges: bright area denotes elevation under $4 \mathrm{~m}$ asl (meters above sea level), light colored areas denotes elevations of $4 \mathrm{~m}$ to $8 \mathrm{~m}$ asl, and dark area represents high grounds with elevation above $8 \mathrm{~m}$ asl. Wide areas with elevation under $8 \mathrm{~m}$ located to the north of the observation area indicates low flatlands, while some to the south located along the riverbank. The box with numbers 1 and 2 denotes specific area of interest in the discussion with the main focus of this paper is in area 1 . The contour data is segmented with watershed segmentation method to find the watershed boundary pattern. This pattern is shown in Figure 4. The segmentation data is then correlated with the original data to verify the pattern locations. The process is illustrated in Figure 5. 


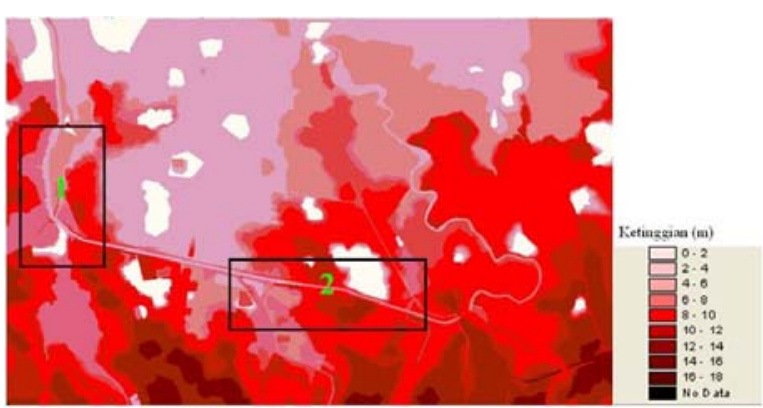

Figure 3. Surface Elevation

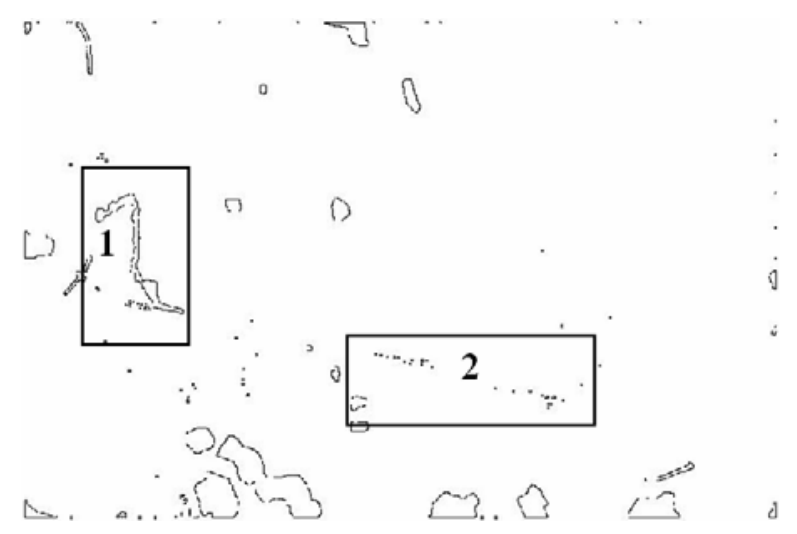

Figure 4. Watershed Segmentation of Surface Elevation

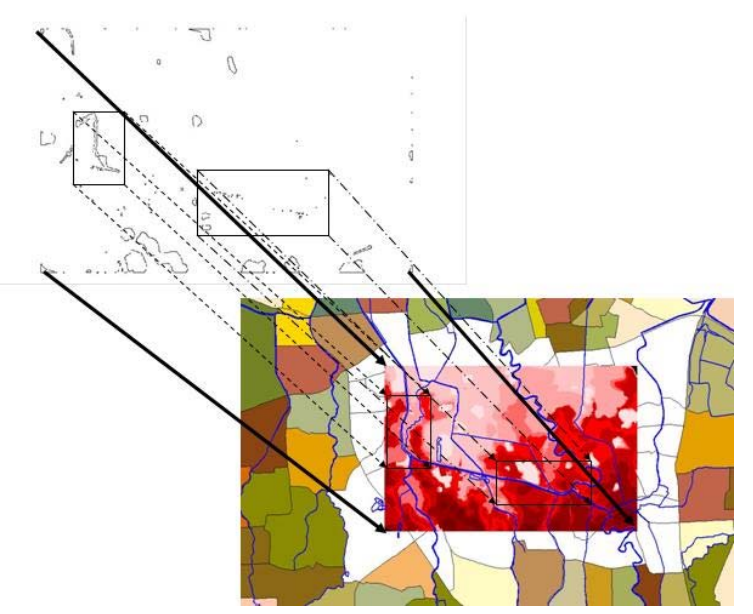

Figure 5. Data Correlation

Figure 6 shows the resulting pattern shows that in area 1 , where there are four dominant pattern groups marked 1 to 4 . Pattern-1 shows consistency with flood canal, pattern-2 is consistent in shape with Melati reservoir albeit at different position, patterns-3 and -4 does not correspond with any known water bodies, and as such, is considered as flood potential area. If the result is consulted with the map of Jakarta, pattern-3 is where Tanah Abang market located, and pattern- 4 is Petamburan high density residential area. These areas are of significant economic importance for Jakarta.

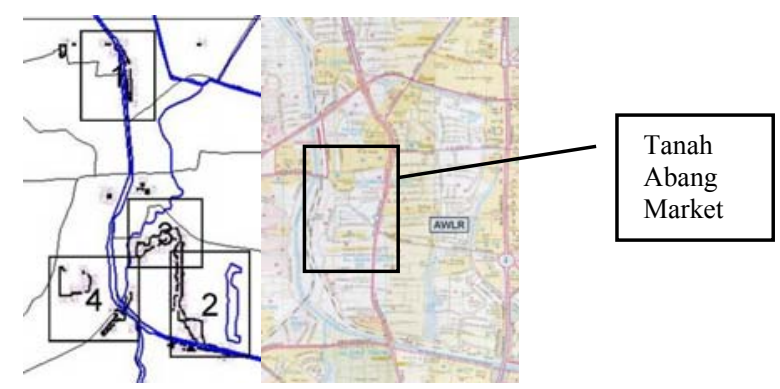

Figure 6. Data Verification

\section{CONCLUSION}

From the data processing in this discussion, it can be concluded that since most of the areas near a river is less than $8 \mathrm{~m}$ above sea level, these areas are categorized as very potent of being flooded, especially if the area is surrounded by higher grounds. Image segmentation based on watershed morphology can indicate patterns that correspond with known water bodies; therefore, if there is no known corresponding water body nearby, it can be regarded as flood potential.

\section{REFERENCES}

[1] United Nations World Health Organization Emergency Situation Report \#6: Floods in Jakarta, Banten and West Java Provinces, Republic of Indonesia, 19 February 2007. $<$ www.who.or.id $>$

[2] Centre for Space Science \& Technology Eduaction in Asia and the Pacific (CSSTEAP), "Applications of Remote Sensing and Geographical Information System in Urban Studies", Indian Institute of Remote Sensing - National Remote Sensing Agency, 2006.

[3] Canada Centre for Remote Sensing, Fundamentals of Remote Sensing.

[4] Kristijono, A., "Metoda Pendugaan Laju Erosi dengan Model Elevasi Digital Berbasis TIN", Remote Sensing \& Geographic Information Systems Yearbook, 1994

[5] Gonzalez, R.C. \& Woods, R.E., Digital Image Processing, Prentice Hall, Inc. United States of America, 2002.

[6] Dinas Pekerjaan Umum Provinsi DKI Jakarta, "Sistem Peringatan Dini Pengendalian Banjir Jakarta", 2007.

[7] United States Geological Survey (USGS), "Landsat Library Database", <www.usgs.gov>. 